\title{
Letter to the Editor: A response to Selvaraj and Boisclair (2019)
}

\author{
S. Leane, ${ }^{1,2}$ M. M. Herlihy, ${ }^{1}$ F. Curran, ${ }^{1,2}$ J. Kenneally, ${ }^{1}$ N. Forde,, 3 C. A. Simintiras, ${ }^{4}$ R. G. Sturmey, ${ }^{4}$ \\ P. Lonergan, ${ }^{2}$ and S. T. Butler ${ }^{1 *}$ \\ ${ }^{1}$ Animal and Grassland Research and Innovation Centre, Teagasc, Moorepark, Fermoy, Co. Cork, P61 P302, Ireland \\ ${ }^{2}$ School of Agriculture and Food Science, University College Dublin, Dublin, D04 V1W8, Ireland \\ ${ }^{3}$ Division of Reproduction and Early Development, Leeds Institute of Cardiovascular and Metabolic Medicine, \\ Faculty of Medicine and Health Science, University of Leeds, Leeds, LS2 9JT, United Kingdom \\ ${ }^{4}$ Center for Cardiovascular and Metabolic Research, Hull York Medical School, University of Hull, Hull, HU6 7RX, United Kingdom
}

Selvaraj and Boisclair (2019) raise 2 concerns with Leane et al. (2018), both of which were discussed in the original manuscript.

First, it is correct that we did not detect a treatment effect on glucose concentrations in uterine luminal fluid. As we pointed out, however, there was a 6- to 8-h delay from termination of the infusion to recovery of the reproductive tract after slaughter and collection of the sample of uterine fluid. Intravenous administration of a large glucose bolus during a glucose tolerance test results in hyperglycemia and hyperinsulinemia, but both glucose and insulin concentrations in blood return to pretreatment baseline concentrations within approximately $1 \mathrm{~h}$ (Patton et al., 2009). Given the rapid kinetics of glucose metabolism, it is likely that any treatment effect on uterine luminal fluid glucose concentrations in the study of Leane et al. (2018) would have disappeared by the time the samples were collected. This point was addressed in the discussion by Leane et al. (2018).

Second, the cows used were in late lactation and had been managed under a pasture-based system during that lactation. Hence, cow milk production up to and during the infusion was moderate. At the time of the infusion, the cows were not hypoglycemic. This point was addressed in the discussion by Leane et al. (2018).

Neither plasma insulin nor plasma fatty acid concentration was significantly affected by treatment. Note that the glucose infusion was continuous at a rate of 750 $\mathrm{g} / \mathrm{d}(\sim 31 \mathrm{~g} / \mathrm{h}, 0.5 \mathrm{~g} / \mathrm{min})$. The pancreatic $\beta$-cells did not have an acute response to the low-dose continuous infusion of glucose, despite a modest increase in glycemia. Interestingly, at the end of the infusion period, plasma glucose concentrations were similar in both treatments and plasma insulin concentrations were starting to diverge, suggesting that a chronic response was unfolding

Received January 6, 2019.

Accepted January 6, 2019.

*Corresponding author: stephen.butler@teagasc.ie over the 7-d infusion period. Regarding the plasma fatty acid concentrations, all cows were in late lactation and were not mobilizing lipid stores when the study took place (plasma fatty acid concentrations $<0.2 \mathrm{mmol} / \mathrm{L}$ ). After bolus administration of either glucose or insulin to cows in positive energy balance, plasma fatty acid concentrations exhibit little or no reduction (e.g., see Sechen et al., 1990; Patton et al., 2009). Hence, it was unlikely that plasma fatty acid concentrations would decline during the infusion, regardless of the absence of a treatment effect on circulating insulin concentrations.

Hypoglycemia in dairy cows is generally confined to the immediate postpartum period, and cows are generally normoglycemic at the end of the voluntary waiting period. For obvious reasons, it would have been difficult to conduct this study during early-lactation hypoglycemia. Our objective was to test the hypothesis that providing extra glucose would affect preimplantation embryo development. To achieve this, we used late-lactation dairy cows for convenience, as they were destined for culling anyway and provided an easy method for the collection of reproductive tracts. We would have preferred to conduct the study using cows at the end of the voluntary waiting period but this was cost prohibitive. Nevertheless, within the context of the study conducted, glucose infusion clearly affected embryo elongation. This effect may have been a direct effect of glucose or an indirect effect through a mechanism not involving insulin or progesterone (neither was affected by glucose infusion). As discussed in Leane et al. (2018), some evidence suggests a direct effect of glucose, and the examples discussed will not be repeated here. We agree that further research on the effects of glucose in preimplantation bovine embryo development is required.

\section{REFERENCES}

Leane, S., M. M. Herlihy, F. Curran, J. Kenneally, N. Forde, C. A Simintiras, R. G. Sturmey, M. C. Lucy, P. Lonergan, and S. T. Butler. 2018. The effect of exogenous glucose infusion on early 
embryonic development in lactating dairy cows. J. Dairy Sci. 101:11285-11296. https://doi.org/10.3168/jds.2018-14894.

Patton, J., J. J. Murphy, F. P. O'Mara, and S. T. Butler. 2009. Responses of North American and New Zealand strains of HolsteinFriesian dairy cattle to homeostatic challenges during early and mid-lactation. Animal 3:251-260.

Sechen, S. J., F. R. Dunshea, and D. E. Bauman. 1990. Somatotropin in lactating cows: Effect on response to epinephrine and insulin. Am. J. Physiol. 258:E582-E588.
Selvaraj, V., and Y. R. Boisclair. 2019. Letter to the Editor: About glucose and early embryo development in cows described by Leane et al. (2018). J. Dairy Sci. 102:2825-2825. https://doi.org/10 .3168/jds.2018-15978. 